\title{
STUDY ON THE INFLUENCE OF SUDDEN CHANGE OF WATER LEVEL ON HIGH FILL CANAL SEGMENT
}

\author{
Chenyang Yuan ${ }^{*}, 1,2$, Xinyong $X u^{1,2}$, Xiangtian Nie ${ }^{1,2,3}$ and Weifeng Bai ${ }^{1,2}$ \\ 1. North China University of Water Resources and Electric Power, School of \\ Water Resources, No.36, Beihuan Road, Zhengzhou, Henan, China; \\ chenyang_yuan@yeah.net; xuxinyong@ncwu.edu.cn; xtnie@126.com; \\ yf9906@163.com \\ 2. North China University of Water Resources and Electric Power, Collaborative \\ Innovation Center of Water Resources Efficient Utilization and Support \\ Engineering, No.36, Beihuan Road, Zhengzhou, Henan, China; \\ chenyang_yuan@yeah.net; xuxinyong@ncwu.edu.cn; xtnie@126.com; \\ yf9906@163.com \\ 3. North China University of Water Resources and Electric Power, Henan Key \\ Laboratory of Water Environment Simulation and Treatment, No.36, Beihuan \\ Road, Zhengzhou, Henan, China; xtnie@126.com
}

\begin{abstract}
Extreme conditions will cause the water level of high fill canal segment to change suddenly, which will affect the velocity and pore pressure of the slope. In this paper, numerical method is used to study the influence of water level sudden change on seepage characteristics of high fill canal segment. HyperMesh software is used to establish the finite element model of typical high fill canal segment under complex foundation conditions. Through the combination of secondary development program and fluid-structure coupling calculation method, the fluid structure coupling effect of canal under sudden change of water level is analyzed in ABAQUS. The results show that when the water level changes suddenly, the pore pressure below the free water surface and the velocity near the free surface will be greatly affected.
\end{abstract}

\section{KEYWORDS}

High fill canal segment, Sudden change of water level, Water conveyance project, Rainfall infiltration, Fluid-structure coupling

\section{INTRODUCTION}

Water resources are an important guarantee for production and life in modern society. Water transfer project is a major strategic infrastructure to realize the optimal allocation of water resources, promote the sustainable development of economy and society, and ensure and improve people's livelihood. In China, The Eastern and Central Routes of the South-to-North Water Transfer Project (SNWTP) consist of a long open canal, inverted siphon, aqueduct and complex hydraulic structures [1] (Figure 1), and they divert water from the Yangtze River to China's arid northern regions. The construction work of the Central Route started on 30 December 2003 and began to supply water on 12 December 2014 [2], in which the concrete construction technology of water box culvert is used in the construction process. The SNWTP mostly adopts the open channel water conveyance mode, and the channel adopts the trapezoidal cross section. In order to prevent seepage and reduce roughness, the whole section is lined. The Central Route of SNWTP is $1431.95 \mathrm{~km}$, and the topography along the main canal is complex. With the comprehensive influence of the project in the 


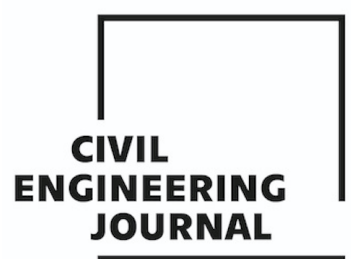

Article no. 56

THE CIVIL ENGINEERING JOURNAL 3-2021

construction and operation period, its reliability, stability and durability are related to seepage, especially when the extreme conditions occur, for example water level suddenly change, the influence on the high fill canal segment needs to be further studied.

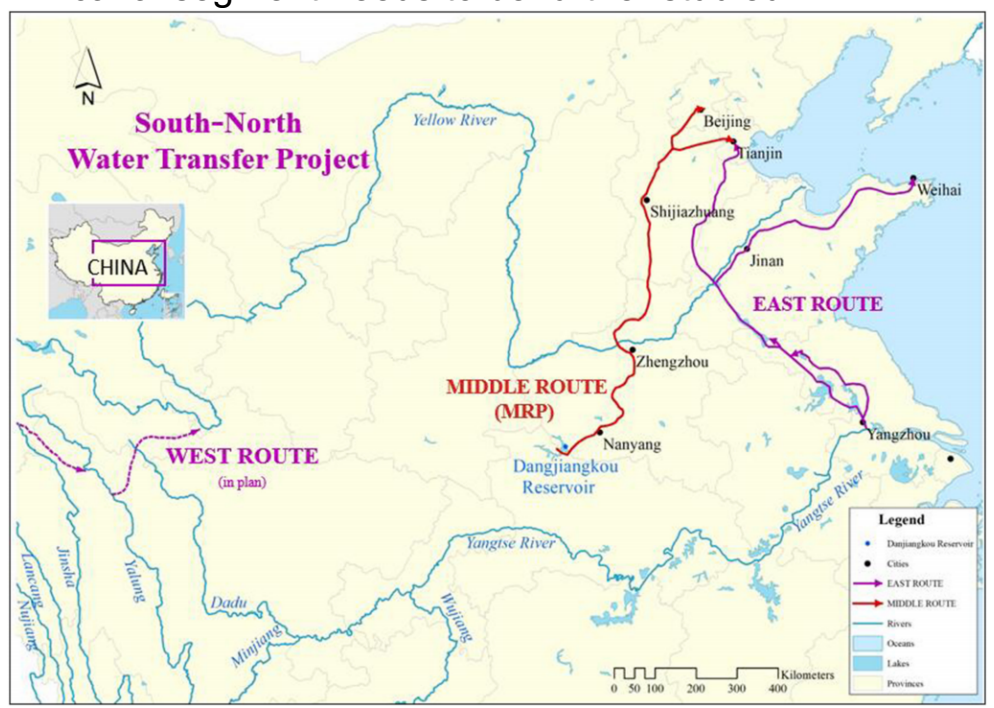

Fig. 1 - Sketch of Central Route of the SNWTP [1]

The soil is composed of more complex porous media. In the soil structure of channel slope, the change of water level causes the continuous change of underground seepage field; at the same time, due to the effect of gravity, the settlement of the channel continuously changes in a long period of time, resulting in the continuous change of structural stress, thus forming the interaction of seepage field and stress field. The seepage field and stress field in soil interact with each other [3]. When there is water head difference in soil, the water in the pore will flow and produce hydrodynamic pressure, namely seepage volume force. The seepage volume force acts on the soil for a long time in the form of external load, which makes the stress field of rock and soil change greatly [4], and the change of stress field will cause the change of displacement field of soil particles, and the spatial position between soil particles will change. After a series of changes mentioned above, the porosity of the soil changes [5], which affects the coefficient of hydraulic conductivity of the soil, and finally changes the seepage field in the soil. CAI and Ugai [6] evaluated the slope stability under rainfall infiltration based on shear strength reduction technology and considering the non-coupling condition of seepage and deformation, combined with statistical and observation methods. Rahardjo et al. [7] studied the influencing factors of slope stability under the condition of rainfall infiltration, and found that slope instability mainly depends on rainfall intensity and soil properties, and other influencing factors are slope type and groundwater level. Baum et al. [8] established the saturated and unsaturated transient rainfall infiltration model, which connected the groundwater transient, unsaturated hydraulic conductivity analysis and groundwater pressure diffusion, and predicted the time and main source area of landslide caused by rainfall. Rahardjo et al. [9] analyzed the stability of residual soil slope under the condition of rainfall infiltration considering different groundwater level, rainfall intensity and soil properties, and the results showed that they were in good agreement with the trend in the parameter study. Based on the Green-Ampt infiltration model and infinite slope stability model, muntohar et al. [10] analyzed the failure law of shallow slope under rainfall infiltration. The proposed model can be used as the first-order approximation to estimate the occurrence time and sliding depth of shallow landslide caused by rainfall. Tsai et al. [11] compared the design scheme with the actual case data, and investigated the influence of unit weight and unsaturated shear strength as a function of saturation on shallow landslide triggered by rainfall infiltration. Borja et al. [12] established a finite element model coupling solid deformation with fluid pressure in unsaturated soil to evaluate slope stability. Rahimi et al. [13] applied three rainfall modes to analyze the transient seepage of soil slope, and applied the calculation results of pore water pressure to the stability 
analysis to study the influence factors of rainfall induced slope failure. Zhang et al. [14] analyzed the slope stability under the condition of rainfall infiltration, summarized the variation law of rainfall infiltration, and discussed the main causes of landslide, so as to provide a certain guarantee for the slope stability. Zhang et al. [15] used the numerical method to analyze the delay phenomenon and influencing factors of slope caused by rainfall infiltration, and determined that the possibility of delay phenomenon is higher when the slope is smaller or slower.

In recent years, many scholars have done a lot of research on fluid-structure coupling calculation method and models. Based on the three-dimensional elastic-plastic finite element theory, Bian et al. [16] proposed a seepage stress coupling method for lining structure. Deng et al. [17] combined the finite element method and the adaptive genetic algorithm, established a model based on the stress seepage coupling model and applied to the highway tunnel, and determined the initial hydraulic conductivity coefficient of the formation and the lateral pressure coefficient of the initial insitu stress through the back analysis method. Yang et al. [18] described and considered the coupling effect of seepage and stress, established a seepage stress cross coupling anisotropic numerical model, and used it to analyze the influence of joint principal direction on rock mass anisotropy. The results show that the anisotropy of rock mass has great influence on stress distribution, hydraulic conductivity and failure area. Godt et al. [19] provided a transient hydraulic conductivity analysis method to analyze a series of soil texture and landslide prone hillsides, and to predict the location and time of shallow landslide caused by rainfall. Garcia et al. [20] described the process of one-dimensional soil column rainfall infiltration based on the multi-phase coupling elastic viscoplastic finite element analysis formula of porous media theory, and numerically analyzed the generation and deformation of pore water pressure when rainfall was applied to soil. Mallari et al. [21] compared and analyzed the applicability of Horton and green amp infiltration models in overland flow, and considered that compared with Horton equation, Green-Ampt equation can more accurately describe the antecedent water content condition and flow process in soil. Wang et al. [22] combined the Green-Ampt model with the law of mass conservation to establish a rainfall infiltration model considering vertical and parallel slope seepage. Based on the Saint Venant continuity and momentum equation of surface runoff, the Green-Ampt model and explicit finite difference method were used to calculate the rainfall runoff of embankment slope [23]. Yao et al. [24] proposed SGA model to evaluate the rainfall infiltration process of slope based on the concept of layered soil moisture above the wetting front. Gavin et al. [25] improved the Green-Ampt model by assuming that the matric suction of soil increases linearly with depth after rainfall. Tsai et al. [26] established an MAGM infiltration model considering the dynamic effect of capillary pressure based on the traditional Green-Ampt model. Zeng et al. [27] investigated the macro-mesoscopic characteristics of seepage flow in porous media. Zhai et al. [28] derived a modified Shields number considering the twodimensional seepage. Hou et al. [29] studied the effects of seepage on the long-term stability of cemented gangue fly ash backfill.

Based on the aforementioned introduction, this study explores the influence of sudden change of water level on the high fill canal segment through the combination of secondary development program and fluid-structure coupling calculation method, the fluid structure coupling effect of canal under sudden change of water level is analyzed in ABAQUS. The saturation, velocity and pore pressure of the high fill canal segment were performed.

\section{THE THEORY OF SEEPAGE AND STRESS COUPLING}

\section{Basic model of seepage field}

Generally, the actual engineering materials are porous media in seepage analysis. Under the action of hydraulic gradient, water flows between the pores. Assuming that water and soil are incompressible, the continuity equation of saturated seepage can be written in tensor form, which can be expressed as follows: 


$$
-\frac{\partial}{\partial x_{i}}\left(\rho v_{t}\right)+S=\frac{\partial}{\partial t}(\rho n), i=1,2,3
$$

where, $\rho$ is fluid density; $v_{t}$ is velocity; $n$ is porosity; $S$ is sink source term. For unsaturated seepage, $\theta=n S_{w}, S_{w}$ is saturation, $0 \leq S_{w} \leq 1$, the continuity equation of saturated unsaturated seepage problem is obtained:

$$
\begin{gathered}
-\frac{\partial}{\partial x_{i}}\left(\rho v_{t}\right)+S=\frac{\partial}{\partial t}\left(\rho n S_{w}\right), i=1,2,3 \\
-\frac{\partial}{\partial x_{i}}\left(\rho v_{x}\right)+\frac{\partial}{\partial y_{i}}\left(\rho v_{y}\right)+\frac{\partial}{\partial z_{i}}\left(\rho v_{z}\right)=-\frac{\partial}{\partial t}\left(\rho n S_{w}\right)+S
\end{gathered}
$$

Darcy's law for unsaturated soils:

$$
v_{i}=-k_{i j} k_{r}(\theta) \frac{\partial H}{\partial x_{j}}, i, j=1,2,3
$$

In the continuity equation:

$$
\frac{\partial}{\partial x_{i}}\left(\rho k_{i j} k_{r}(\theta) \frac{\partial H}{\partial x_{j}}\right)+S=\frac{\partial}{\partial t}\left(\rho n S_{w}\right), i, j=1,2,3
$$

where, $k_{i j}$ is the saturated hydraulic conductivity tensor; $k_{r}(\theta)$ is the ratio of the hydraulic conductivity coefficient of unsaturated zone to that of saturated zone. Considering that there is a functional relationship between $\theta, h$ and $k_{r}, k_{r}(\theta)=k_{r}(\theta(h)), h$ is the pressure head, $z$ is the position head:

$$
\frac{\partial \theta}{\partial t}=\frac{\partial \theta}{\partial h} \frac{\partial h}{\partial t}
$$

The following differential equation of saturated and unsaturated seepage flow can be obtained by taking the water capacity $C=\frac{\partial \theta}{\partial h}$ into formula (6) with water content instead of saturation, where the water capacity $C$ is equal to zero in the saturated area and $S_{s}$ is the unit storage capacity.

$$
\frac{\partial}{\partial x_{i}}\left(k_{i j} k_{r}(h) \frac{\partial h}{\partial x_{j}}+k_{i 3} k_{r}(h)\right)+S=\left(C(h)+\beta S_{s}\right) \frac{\partial h}{\partial t}
$$

When the time factor is not considered, the saturated unsaturated differential equation of steady seepage can be expressed:

$$
\frac{\partial}{\partial x_{i}}\left(k_{i j} k_{r}(h) \frac{\partial h}{\partial x_{j}}+k_{i 3} k_{r}(h)\right)+S=0
$$

For the saturated unsaturated seepage field, the whole seepage region can be divided into saturated region and unsaturated region; the boundary conditions include the head boundary, known flow boundary, free surface boundary and overflow surface boundary. Where $q$ is the normal flow, 
outward is positive; $n$ is the cosine of the external normal direction; $t_{0}$ is the initial time; $\Gamma_{1}$ is the known head boundary; $\Gamma_{2}$ is the known flow boundary; $\Gamma_{3}$ is the free surface boundary; $\Gamma_{4}$ is the over-flow surface boundary.

Initial conditions:

$$
h\left(x, y, z, t_{0}\right)=h_{0}\left(x, y, z, t_{0}\right)
$$

Water head boundary conditions:

$$
\left.h(x, y, z, t)\right|_{\Gamma_{1}}=h_{1}(x, y, z, t)
$$

Flow boundary conditions:

$$
-\left.k \frac{\partial h(x, y, z, t)}{\partial n}\right|_{\Gamma_{2}}=q(x, y, z, t)
$$

Free surface boundary conditions:

$$
-\left.k \frac{\partial h(x, y, z, t)}{\partial n}\right|_{\Gamma_{3}}=0,\left.p\right|_{\Gamma_{3}}=0
$$

Overflow surface boundary condition:

$$
-\left.k \frac{\partial h(x, y, z, t)}{\partial n}\right|_{\Gamma_{4}} \geq 0,\left.p\right|_{\Gamma_{4}}<0
$$

\section{Calculation theory of seepage field}

When the space domain is assumed to be discretized, the following coupling equations of seepage and stress can be obtained, which $\left[K_{m}\right]$ is the structural stiffness matrix, $(u)$ is the column vector of node displacement, and $(F)$ is the node load of the structure:

$$
\left[K_{m}\right](u)=(F)+\left(F_{s}\right)
$$

\section{Fluid-structure coupling analysis}

The main difference between the saturated and unsaturated regions is the coefficient of hydraulic conductivity. In the saturated region, the coefficient of hydraulic conductivity is generally regarded as a constant, while in the unsaturated region, the coefficient of hydraulic conductivity is a relation between the saturation and the matric suction. In the unsaturated region, the pore water pressure is negative, while in the saturated region, the pore water pressure is positive. Even with these differences, the local differential equations of flow are the same. According to the principle of conservation of mass, the governing differential equation of saturated unsaturated seepage is

$$
\frac{\partial}{\partial x_{i}}\left(k_{i j} k_{r}(y) \frac{\partial h}{\partial x_{j}}+k_{i 3} k_{r}(h)\right)+S=\left(C(h)+\beta S_{s}\right) \frac{\partial h}{\partial t}
$$

where, $k_{r}(h)$ is the relative coefficient of hydraulic conductivity, in the saturated area $k_{r}(h)=1$, in the unsaturated area $k_{r}(h) \in[0,1] ; k_{i j}$ is the saturated hydraulic conductivity tensor; $S_{s}$ is the unit 
water storage coefficient; $C(h)$ is the water capacity, positive pressure area, negative pressure area, $C(h)=\frac{\partial \theta}{\partial h} ; \quad \theta$ is the water content; $\beta$ is the parameter to determine the saturated and unsaturated state, $\beta=0$ in the unsaturated area, $\beta=1$ in the saturated area; $t$ is the time; $S$ is the source sink term. model

The relationship between matric suction and saturation was obtained by Van Genuchten

$$
S_{e}=\left[1+\left(\alpha P_{c}\right)^{n}\right]^{-m}
$$

where, $P_{c}$ is the matric suction; $m, n$ and $\alpha$ are the fitting parameters.

The relationship between parameters $m$ and $n$ can be used by $n=[-m]^{-1}$, then equation (16) can be expressed as:

$$
P_{c}=P_{0}\left[S_{e}^{-1 / m}-1\right]^{1 / n}
$$

where, $P_{0}=1 / \alpha ; S_{e}$ is the effective saturation, $S_{e}=\left(\theta_{w}-\theta_{r}\right) /\left(\theta_{s}-\theta_{r}\right) ; \theta_{s}$ is the saturated volumetric water content; $\theta_{r}$ is the residual volumetric water content; and $\theta_{w}$ is the volumetric water content of the corresponding matrix suction.

\section{SECONDARY DEVELOPMENT PROGRAM}

In order to study the influence of sudden change of water level, an ideal slope model is used to verify the effectiveness of the secondary development program.

\section{Ideal slope model}

The mathematical model established in this section is an ideal slope. The slope angle is $45^{\circ}$ and the slope height is $5 \mathrm{~m}$. The initial groundwater level is $2 \mathrm{~m}$ above the foot of the slope, and the foundation size is $10 \mathrm{~m}$. Based on the above theoretical analysis, the finite element model was established in ABAQUS and shown in Figure 2.

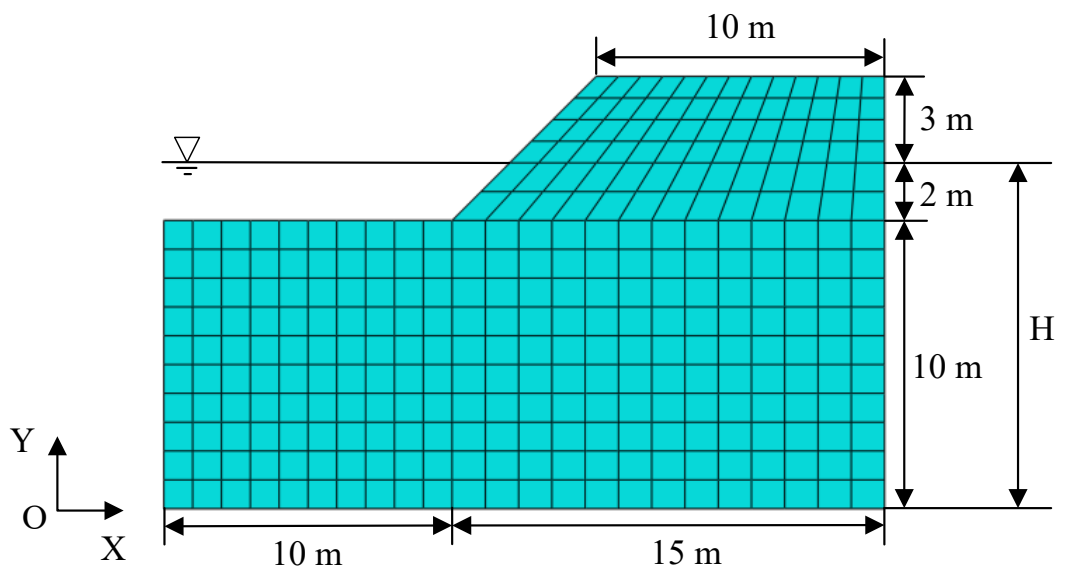

Fig. 2 - Finite element mesh model 


\section{Program code}

When there is a rainstorm or other special circumstances, the water level of the channel will change suddenly in a short time. In ABAQUS, there is no function to directly set the sudden change of water level. In order to further analyse and study the canal segment performance in the case of sudden change of water level, it needs to be realized through secondary development. This research is implemented by FORTRAN program. The calculation flow chart is shown in Figure 3, where $\mathrm{Y}$ is the height value of node on the boundary below water level, $\rho$ is the density of water, $\gamma_{\text {water }}$ is the bulk density of water, $\mathrm{t} 1$ is the time of Step 1, t2 is the time of Step 2, s1 is the water level that decreases in time t0. It is assumed that the water level will drop by $2 \mathrm{~m}$ within 24 hours as an example.

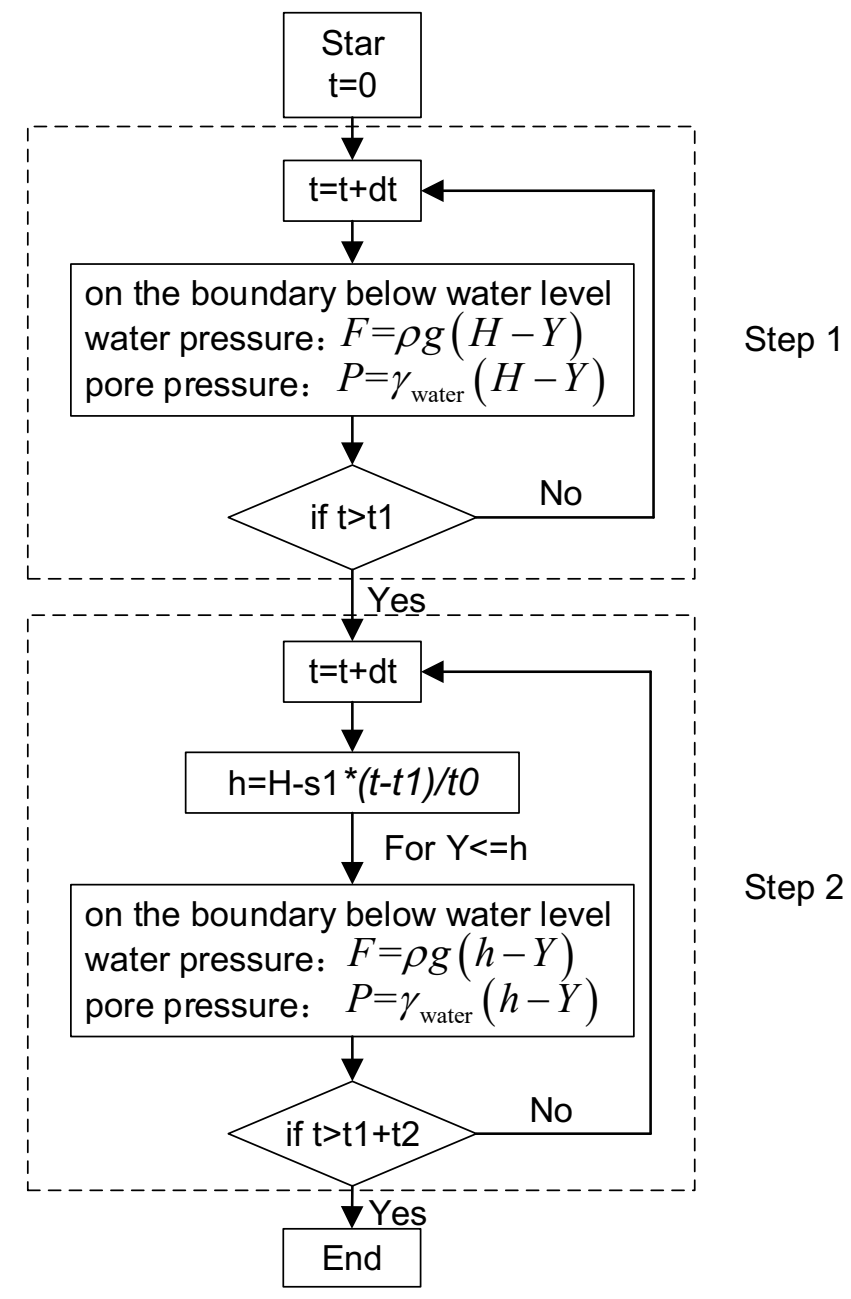

Fig. 3-Calculation flow chart

\section{Analysis of sudden change of water level}

The seepage analysis of ideal model before and after the sudden change of water level is carried out in ABAQUS. Figure 4 shows the distribution of pore pressure before and after the sudden change of water level. The pore pressure distribution after the sudden change of water level is significantly different from the initial state. With the decrease of water level, the phreatic line 
decreases at the slope position. However, due to the change of water level in a short time, the seepage of internal soil changes little, so the position of internal phreatic line changes little.

Figure 5 shows the vertical displacement distribution before and after the sudden change of water level. It can be seen from the figure that due to the influence of seepage, the vertical displacement at the foot of the slope changes from $-2.57 \mathrm{~mm}$ to $-1.85 \mathrm{~mm}$ (positive upward), and the vertical displacement at the middle of the bottom plane of the slope changes from $0 \mathrm{~mm}$ to $1.64 \mathrm{~mm}$.

Through the analysis of ideal model, the rationality of secondary development program is verified, which is helpful to apply to high fill canal segment.

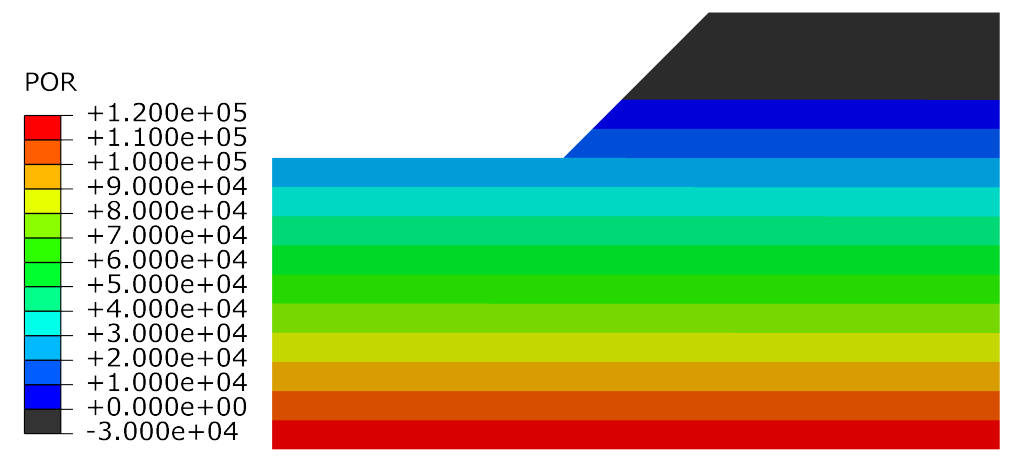

(a)

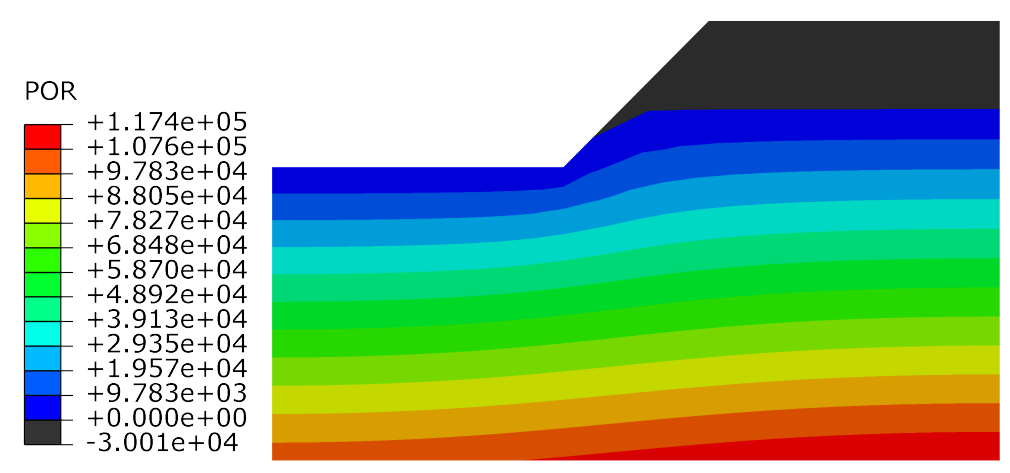

(b)

Fig. 4- The pore pressure nephogram: (a) before sudden change of water level; (b) after sudden change of water level
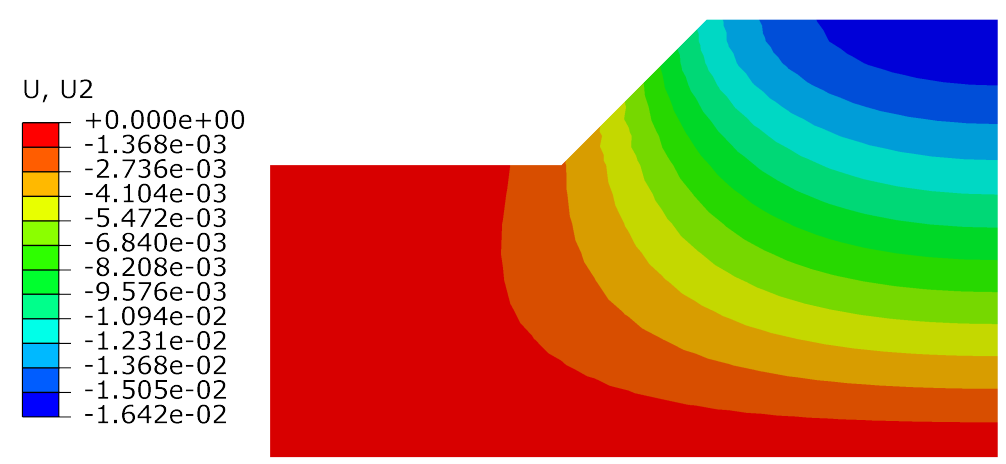

(a)

Fig. 5 - Vertical displacement nephogram: (a) before sudden change of water level; (b) after sudden change of water level 


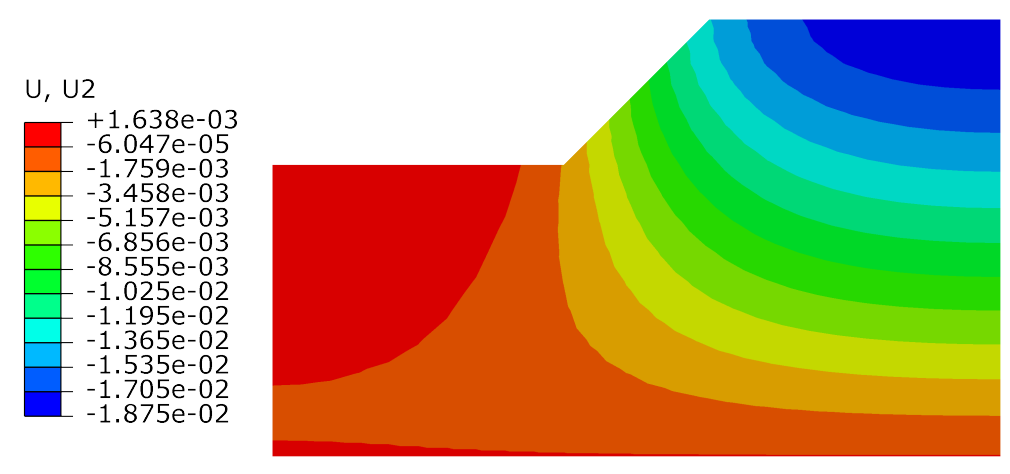

(b)

Fig. 5 - Vertical displacement nephogram: (a) before sudden change of water level; (b) after sudden change of water level

\section{SIMULATION AND DISCUSSION}

\section{The model of high fill canal segment}

The typical high fill canal segment is selected for seepage stress coupling numerical simulation analysis. Because the thickness of lining plate is smaller than that of soil, the element transition is used in HyperMesh to realize the connection between meshes of different sizes, as shown in Figure 6. The model includes: concrete lining slab, asphalt pavement, foundation and fill. In the calculation, CPE4P coupling element with high accuracy is selected as the material element of the model, and the calculated mechanical parameters of the material model are shown in Table 1. It should be pointed out that the positions of silty clay and compacted silty clay are foundation and filling respectively.

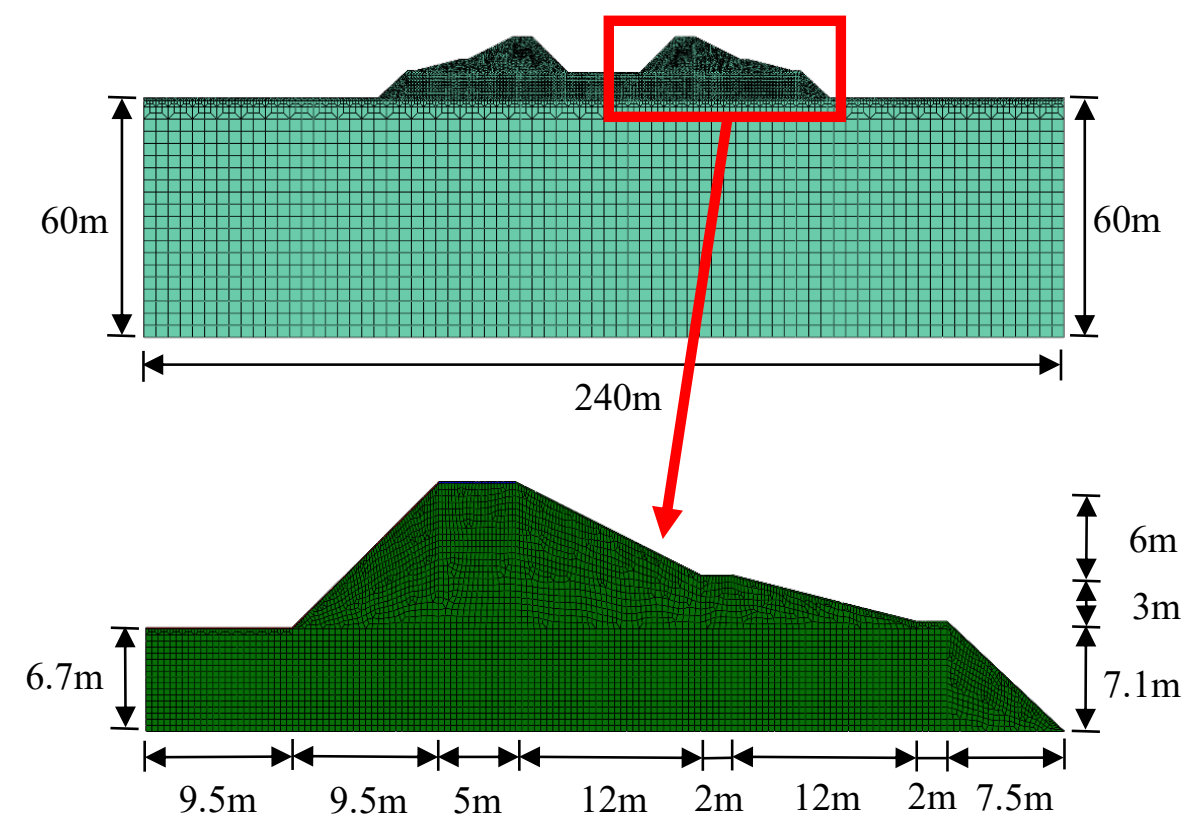

Fig. 6 - The finite element model of high fill canal segment 


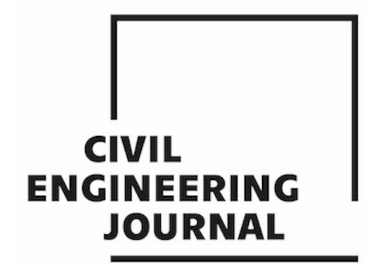

Article no. 56

THE CIVIL ENGINEERING JOURNAL 3-2021

Tab. 1: Calculation mechanical parameters of material

\begin{tabular}{|c|c|c|c|c|c|c|c|}
\hline $\begin{array}{c}\text { material } \\
\text { type }\end{array}$ & $\begin{array}{c}\text { compression } \\
\text { modulus (MPa) }\end{array}$ & $\begin{array}{c}\text { density } \\
\left(\mathrm{kg} \cdot \mathrm{m}^{-3}\right)\end{array}$ & $\begin{array}{c}\text { cohesion } \\
(\mathrm{kPa})\end{array}$ & $\begin{array}{c}\text { friction angle } \\
\left({ }^{\circ}\right)\end{array}$ & porosity & $\begin{array}{c}\text { hydraulic } \\
\text { conductivity } \\
(\mathrm{m} / \mathrm{s})\end{array}$ & $\begin{array}{c}\text { grain size } \\
(\mathrm{mm})\end{array}$ \\
\hline silty clay & 23 & 2020 & 42.0 & 25.0 & 0.48 & $3.5 \mathrm{e}-8$ & 0.005 \\
\hline $\begin{array}{c}\text { compacted } \\
\text { silty clay }\end{array}$ & 22 & 2010 & 36.6 & 17.6 & 0.50 & $7.3 \mathrm{e}-7$ & 0.005 \\
\hline
\end{tabular}

\section{Seepage analysis of sudden change of water level}

The lining plate has the function of anti-seepage and reducing roughness under normal conditions. During the operation of SNWTP, due to various factors such as uneven settlement and rainfall, the lining plate will crack, swell and collapse, which will make the lining plate lose its antiseepage function. ABAQUS provides special "displacement pore pressure coupling elements" for solving seepage stress coupling problems. The pore pressure of these elements is linear distribution, and the displacement can be taken as the first-order or second-order distribution function, which can be used to solve porous media seepage problems of plane strain, axisymmetric and $\mathrm{H}$ dimensional problems.

In order to better analyse the calculation results, the top A, middle $B$ and bottom $C$ of the canal slope are selected as the characteristic points to analyse the seepage characteristics of the canal slope (Figure 7).

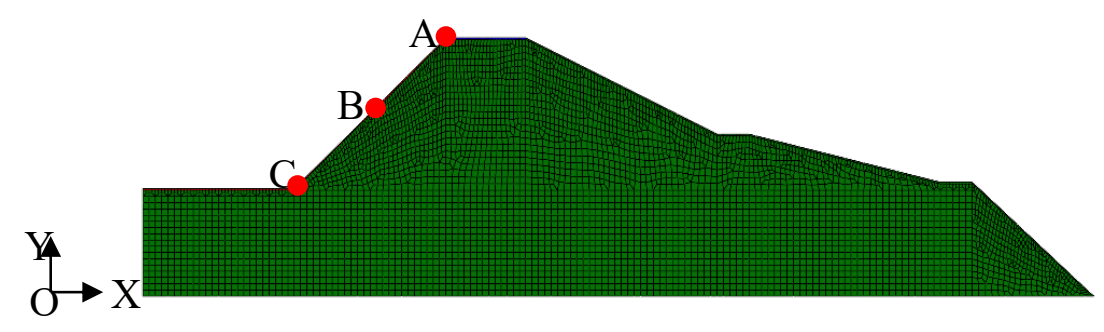

Fig. 7 - Distribution map of characteristic points

When there is rainstorm, leakage or other extreme conditions, the water level of the channel will rise or fall in a short time. In order to further analyze and study the seepage characteristics of the sudden rise and fall of water level, it needs to be realized through the secondary development in ABAQUS. In this study, according to the dynamics of actual changes in the channel, FORTRAN program is used to realize the situation of water level sudden drop of $0.5 \mathrm{~m}$ (case 1) and sudden rise of $0.5 \mathrm{~m}$ (case 2) within 3 hours, and two analysis steps are set: Step 1 is seepage steady analysis, Step 2 is seepage transient analysis, and subroutine plays a role in Step 2.

Figure 8 shows the distribution of pore pressure before and after the sudden change of water level with two cases. And the Table 2 shows the results of pore pressure for $A, B$, and $C$. For the normal case, the Figure 8(a) shows that pore pressure nephogram under design water level when lining plate and composite geomembrane fail at the same time, which indicates that when the antiseepage effect of lining plate fails, the water in the channel will seep into the soil, which may lead to the outward leakage of river water. It can be seen from the Figure 8 that the sudden drop or rise of water level will lead to the drop or rise of the pore water pressure at $B$ and $C$, and the change of pore water pressure at A point is not obvious, because a point is above the free water surface, the pore water pressure is negative, and there is no significant change. 


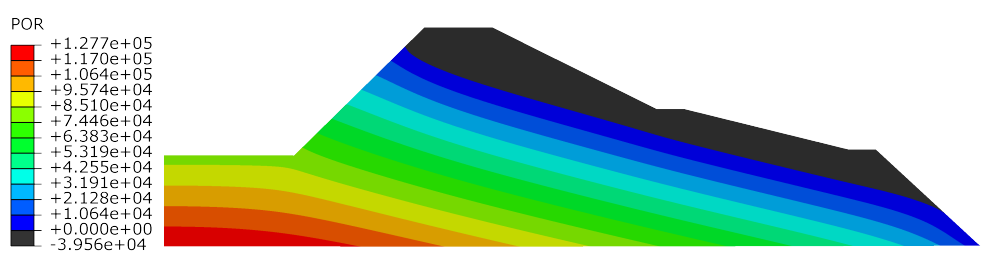

(a)

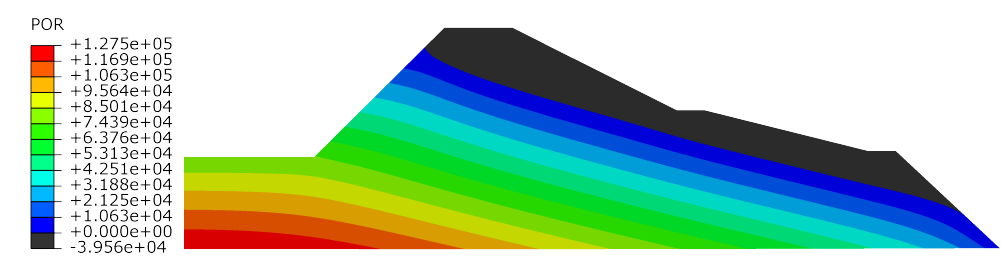

(b)

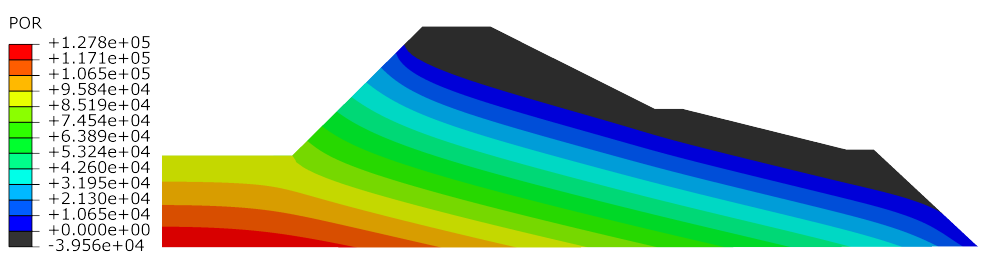

(c)

Fig. 8 - The pore pressure nephogram of high fill canal segment: (a) normal; (b) case 1; (c) case 2

Tab. 2: Pore pressure of seepage analysis $(\mathrm{kPa})$

\begin{tabular}{|c|c|c|c|}
\hline Type & normal & case1 & case 2 \\
\hline A & -25.63 & -25.63 & -25.63 \\
\hline B & 32.30 & 27.30 & 37.23 \\
\hline C & 80.00 & 75.00 & 85.00 \\
\hline
\end{tabular}

Figure 9 shows the velocity vector diagram of grid integration point before and after the sudden change of water level with two cases. It can be seen form the figure that the sudden change of water level leads to obvious change of velocity near the free water surface, but not obvious change inside the fill. This is because the time of sudden change of water level is short, and it has not caused too much impact on the inside of the fill.

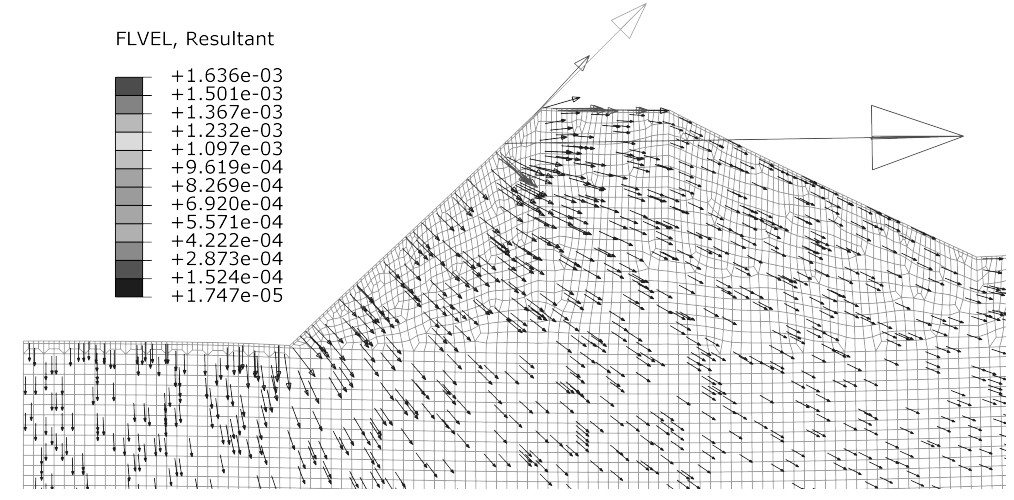

(a)

Fig. 9 - The velocity vector diagram of grid integration point of high fill canal segment: (a) normal 


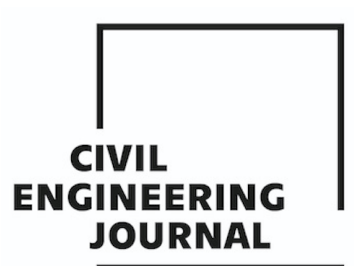

Article no. 56

NGINEERING

THE CIVIL ENGINEERING JOURNAL 3-2021

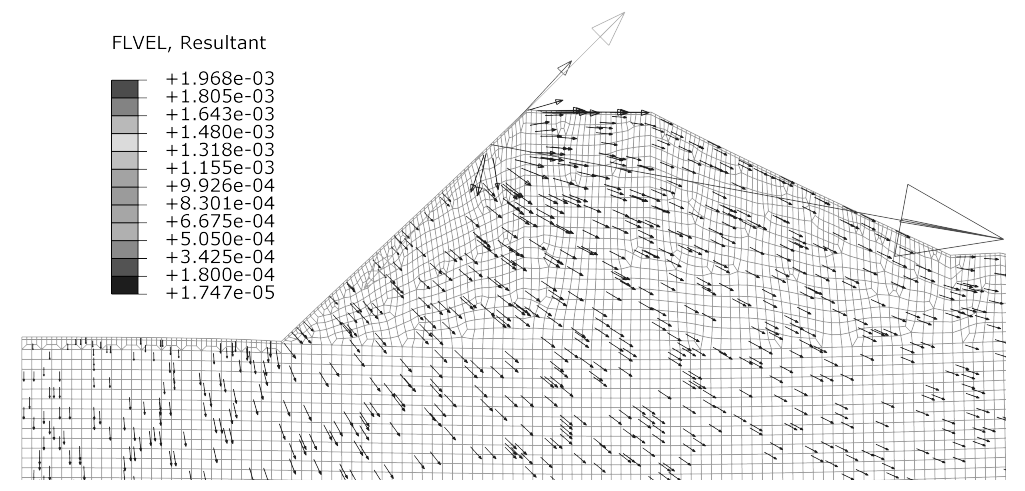

(b)

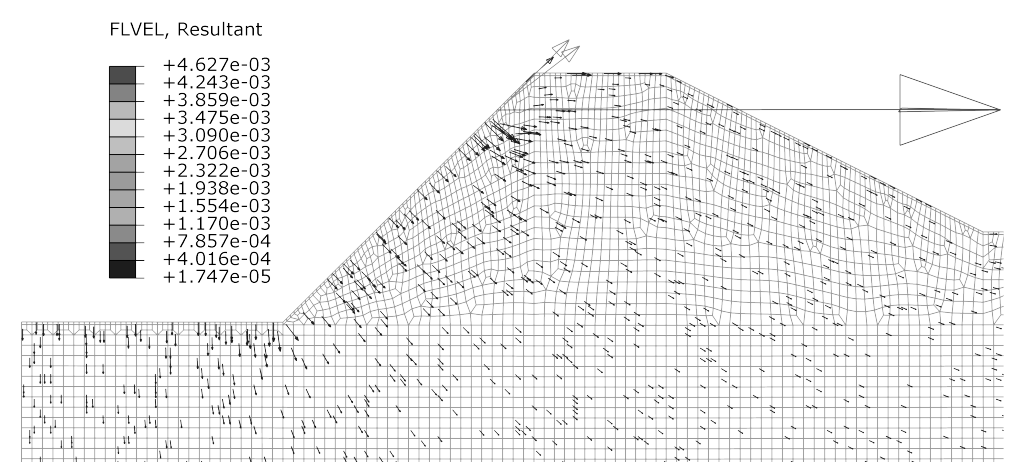

(c)

Fig. 9 - The velocity vector diagram of grid integration point of high fill canal segment: (a) normal; (b) case 1; (c) case 2

\section{CONCLUSION}

This study has focused on the influence of water level sudden change on seepage characteristics of high fill canal segment. FORTRAN program was used to realize the situation of water level sudden change. One ideal slope model was used to verify the rationality of secondary development program. For high fill canal segment, the two cases with sudden drop of $0.5 \mathrm{~m}$ and sudden rise of $0.5 \mathrm{~m}$ in 3 hours were studied. Considering the fluid-structure interaction, the change of seepage performance under the condition of sudden change of water level is analyzed. The conclusions is as follows:

1. The FORTRAN program given in this paper can effectively simulate the sudden change of water level. Under the action of sudden change of water level, it will lead to the change of pore pressure below the free water surface, but the change of pore pressure above the free water surface is not obvious; the velocity near the free water surface has a great influence, but it has little influence on the velocity inside the fill due to the short time.

2. When the anti-seepage effect of lining plate fails, the water in the channel will seep into the soil, which may lead to the outward leakage of river water, which will result in the structural failure.

3. The safety for earthquake action, the uneven settlement of the joint parts of different buildings and the influence of different site conditions on seepage can be studied in the near future.

4. For high fill canal segment, it is suggested to increase the anti-seepage measures at the external slope toe in the design process. 


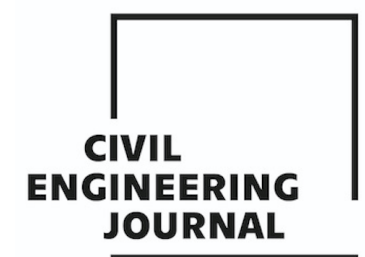

Article no. 56

THE CIVIL ENGINEERING JOURNAL 3-2021

\section{ACKNOWLEDGEMENTS}

This research was funded by the National Key Research and Development Project (grant no. 2018YFC0406901), National Natural Science Foundation of China (grant nos. 51979109 and 51679092), and Scientific Research Project of North China University of Water Resources and Electric Power (grant no. 201811007).

\section{REFERENCES}

[1] Yang Y., Lei X., Long Y., et al., 2019. A novel comprehensive risk assessment method for sudden water accidents in the Middle Route of the South-North Water Transfer Project (China). Science of The Total Environment. 698, 134167.

[2] Dong J , Lai S , Wang N , et al., 2021. Multi-scale deformation monitoring with Sentinel-1 InSAR analyses along the Middle Route of the South-North Water Diversion Project in China. International Journal of Applied Earth Observation and Geoinformation, 100:102324.

[3] Yang T. H., Jia P., Shi W. H., et al., 2014. Seepage-stress coupled analysis on anisotropic characteristics of the fractured rock mass around roadway. Tunnelling and Underground Space Technology incorporating Trenchless Technology Research. 43, 11-19.

[4] Zhang M., Dong Y., Sun P., 2012. Impact of reservoir impoundment-caused groundwater level changes on regional slope stability: a case study in the Loess Plateau of Western China. Environmental Earth Sciences. 66(6), 1715-1725.

[5] Leong E. C., Rahardjo H., 2012. Two and three-dimensional slope stability reanalyses of Bukit Batok slope. Computers and Ge-otechnics. 42(3), 81-88.

[6] Ugai C., 2004. Numerical analysis of rainfall effects on slope stability. International journal of geomechanics. 69-78.

[7] Rahardjo H., Ong T. H., Rezaur R. B., Leong E. C., 2007. Factors controlling instability of homogeneous soil slopes under rainfall. Journal of Geotechnical \& Geoenvironmental Engineering. 15321543.

[8] Baum R. L., Godt J. W., Savage W. Z., 2010. Estimating the timing and location of shallow rainfallinduced landslides using a model for transient unsaturated infiltration. Journal of Geophysical Research-Earth Surface. 115, 26.

[9] Rahardjo H., Nio A. S., Leong E. C., Song N. Y., 2010. Effects of Groundwater Table Position and Soil Properties on Stability of Slope during Rainfall. Journal of Geotechnical and Geoenvironmental Engineering. 136, 1555-64.

[10] Muntohar A. S., Liao H. J., 2010. Rainfall infiltration: infinite slope model for landslides triggering by rainstorm. Natural Hazards. 54, 967-84.

[11] Tsai T. L., Chen H. F., 2010. Effects of degree of saturation on shallow landslides triggered by rainfall. Environmental Earth Sciences. 59, 1285-95.

[12] Borja R. I., White J. A., 2010. Continuum deformation and stability analyses of a steep hillside slope under rainfall infiltration. Acta Geotechnica. 5, 1-14.

[13] Rahimi A., Rahardjo H., Leong E. C., 2011. Effect of Antecedent Rainfall Patterns on Rainfall-Induced Slope Failure. Journal of Geotechnical and Geoenvironmental Engineering. 137, 483-91.

[14] Zhang L. L., Zhang J., Zhang L. M., Tang W. H., 2011. Stability analysis of rainfall-induced slope failure: a review. Proceedings of the Institution of Civil Engineers-Geotechnical Engineering. 164, 299-316.

[15] Zhang J., Li J. T., Lin H., 2018. Models and influencing factors of the delay phenomenon for rainfall on slope stability. European Journal of Environmental and Civil Engineering. 22, 122-36.

[16] Bian K., Xiao M., Chen J., 2009. Study on coupled seepage and stress fields in the concrete lining of the underground pipe with high water pressure. Tunnelling and Underground Space Technology. 24, 287-295

[17] Deng X. H., Yuan D. Y., Yang D. S., Zhang C. S., 2017. Back Analysis of Geomechanical Parameters of Rock Masses Based on Seepage-Stress Coupled Analysis. Mathematical Problems in Engineering. 13.

[18] Yang T. H., Jia P., Shi W. H., Wang P., Liu H. L., Yu Q. L., 2014. Seepage-stress coupled analysis on anisotropic characteristics of the fractured rock mass around roadway. Tunnelling and Underground Space Technology. 43, 11-19. 
[19] Godt J. W., Sener-Kaya B., Lu N., Baum R. L., 2012. Stability of infinite slopes under transient partially saturated seepage conditions. Water Resources Research. 48, 14.

[20] Garcia E., Oka F., Kimoto S., 2011. Numerical analysis of a one-dimensional infiltration problem in unsaturated soil by a seepage-deformation coupled method. International Journal for Numerical and Analytical Methods in Geomechanics. 35, 544-68.

[21] Mallari K. J. B., Arguelles A. C. C., Kim H., et al., 2015. Comparative analysis of two infiltration models for application in a physically based overland flow model. Environmental Earth Sciences. 74(2), 1579-1587.

[22] Wang D. J., Tang H. M., Zhang Y. H., et al., 2017. An improved approach for evaluating the time dependent stability of colluvial landslides during intense rainfall. Environmental Earth Sciences. 76(8), 321.

[23] Asim, Krishna, Sajjan, et al., 2013. Rainfall-runoff modelling of railway embankment steep slopes. Hydrological Sciences Journal. 58(5), 1162-1176.

[24] Yao W., Li C., Zhan H., et al., 2019. Time dependent slope stability during intense rainfall with stratified soil water content. Bulletin of Engineering Geology and the Environment. 78(7), 4805-4819.

[25] Gavin K., Xue J., 2008. A simple method to analyze infiltration into unsaturated soil slopes. Computers and Geotechnics. 35(2), 223-230.

[26] Tsai Y. Z., Liu Y. T., Wang Y. L., et al., 2018. Effects of the Grain Size on Dynamic Capillary Pressure and the Modified Green-Ampt Model for Infiltration. Geofluids. 2018, 1-11.

[27] Zeng F., Guo Z., Wang L., et al., 2020. Experimental investigation on macro-mesoscopic characteristics of seepage flow in transparent porous media. Applied Ocean Research. 105, 102424.

[28] Zhai H., Jeng D. S., Guo Z., et al., 2021. Impact of two-dimensional seepage flow on sediment incipient motion under waves. Applied Ocean Research. 108, 102510.

[29] Hou J., Guo Z., Li J., et al., 2020. Study on triaxial creep test and theoretical model of cemented ganguefly ash backfill under seepage-stress coupling. Construction and Building Materials. 